\title{
A new preparation technology of structural- gradient materials without a brittle transition zone in a Mn-Si-Cr-B bainitic cast steel
}

\author{
Yu-guang Zhao, Zhe Wang, *Xiao-feng Xu, Ming-zhe Zhang, and Wen-qiang Jiang \\ Key laboratory of Automobile Materials of Ministry of Education \& School of Materials Science and Engineering, Nanling Campus, Jilin \\ University, No. 5988 Renmin Street, Changchun 130025, China
}

\begin{abstract}
In the present work, a unique gradient cooling heat treatment process (GCHT) for a Mn-Si-Cr-B bainitic cast steel was developed, and microstructure and mechanical properties were examined by OM, SEM, EBSD and a uniaxial tensile test. The results showed that the structural-gradient-material (SGM) with a gradient microstructure from granular bainite to martensite was successfully produced, and it exhibited a good ductility $(\sim 13.8 \%)$ at one end and an excellent ultimate strength $(\sim 1,720 \mathrm{MPa})$ at the other end. In between the bainite and martensite, a transition region with a superior combination of tensile strength and ductility (1,700 MPa and $11.1 \%)$ was obtained, which is different from the normal knowledge of a brittle transition region. Moreover, through changing the gradient of cooling rate, the optimized SGM with a new gradient microstructure from pearlite to martensite showed a more stable structural gradient and an improved ductility $(22.8 \%)$ at one end. The microstructure variation in the sample was mainly related to the carbon diffusion rate during heat treatment, and the diffusion rate could be controlled by regulating the cooling velocity. Therefore, the SGMs with different gradient microstructures could be designed to meet the needs of different properties. As a result, this work provides a new approach for preparation of the gradient structured steel, which has potential for practical application for dual-property automobile parts.
\end{abstract}

Key words: bainitic cast steel; gradient cooling heat treatment; structural-gradient-materials
CLC numbers: TG142.33
Document code: A
Article ID: 1672-6421(201804-283-08

\begin{abstract}
T tructural-gradient-materials (SGMs), because of their $\checkmark$ characteristic of different positions with different mechanical properties, have been paid more and more attention for special features requested by some certain applications. With the development of materials science, many manufacturing techniques for gradient materials have been developed, including powder metallurgy ${ }^{[1]}$, chemical vapor deposition ${ }^{[2]}$, diffusion bonding ${ }^{[3]}$ and laser smelting deposition ${ }^{[4]}$, etc.

As is known, investigation on designing \& manufacturing technology for automobile components has always been a fundamental and critical issue. Especially, the complicated parts may need to meet different requirements of performance in different positions. For example, the rear axle, on the one hand, is required to provide high strength and rigidity at both
\end{abstract}

\section{*Xiao-feng $\mathrm{Xu}$}

Male, born in 1986, Ph. D, Associate professor. His research interests mainly focus on the light-weight materials and strengthening- toughening of steels.

E-mail: xuxiaofeng@jlu.edu.cn

Received: 2018-02-28; Accepted: 2018-05-14 ends to bear the reaction force and bending moment from the drive wheel; and on the other hand, it is also needed to possess reasonable ductility at the middle part to prevent brittle fracture at a low strain level. In general, the high performance axle tube is connected with the axle by welding to enhance the strength at ends after the main body is produced by monolithic casting. However, the additional step of assembly not only increases production costs but also limits the movement of the axle during turning maneuvers process. Moreover, it's very difficult to ensure the quality of the junction ${ }^{[5]}$. Therefore, the gradient structural material is an ideal material for such a type of components. It would be possible to achieve the objective of monolithic manufacturing for axle housings.

Since Davenport and Bain et al. discovered bainite ${ }^{[6]}$, bainitic steels have been widely used in pipeline steel, construction machinery, and shipbuilding industry due to its excellent combination of tensile strength and total elongation ${ }^{[7,8]}$. Recently, improving mechanical properties via controlling bainite transformation in steel at various cooling rates has been extensively investigated. Zhang et al. studied the influence of different 
cooling rates on C-Si-Mn TRIP steel ${ }^{[9]}$. The fully martensitic microstructure was obtained at the fastest cooling rate. And as the cooling velocity decreased, granular bainite, polygonal ferrite and pearlite were formed. The rapid cooling rate could depress the formation of ferrite and pearlite and accelerate the formation of granular bainite and martensite, which resulted in higher hardness. Besides, Sung et al. investigated high-strength bainitic steel plates fabricated by varying the cooling rates ${ }^{[10]}$. It was found that the volume fraction of microstructures increased in the order of granular bainite (GB), acicular ferrite (AF), bainite ferrite (BF) and martensite $(\mathrm{M})$ with increasing the cooling rate; the yield and tensile strengths increased and the elongation decreased with increasing the cooling velocity. These research studies revealed that different microstructures with different properties can be obtained by controlling the cooling rates.

The studies mentioned above concentrated on workpieces with uniform microstructure under conditions of continuous cooling. A preparation method for the gradient microstructure of steel via heat treatment is still a critical problem. Hence, this research tried to address this issue. The gradient cooling process was designed to acquire the gradient microstructure in a Mn-SiCr-B bainitic cast steel. The mechanism of structural evolution during heat treatment and corresponding mechanical properties were also investigated in this paper.

\section{Experimental procedures}

\subsection{Preparation of steel}

Billets with the alloy compositions of a Mn-Si-Cr-B bainitic cast steel were prepared from ferrosilicon, ferromanganese, ferrochrome, ferrovanadium, ferrotitanium, ferroboron, rare earth and Q235 steel. All the raw materials were melted in a medium frequency induction furnace. When the melt temperature increased to $1,600{ }^{\circ} \mathrm{C}$, the molten steel was poured into the Y-shaped sand mold. Manganese was added to suppress austenite to ferrite transformation at high temperature. Silicon was added to suppress carbide precipitation during quenching and tempering steps. A small amount of boron was added to increase the hardenability of the steel and thus replaced the certain expensive alloy elements like $\mathrm{Cr}$ and Mo. Rare earth was added to clean up impurities and improve structure and properties of the steel. Chemical composition of tested steel is listed in Table 1. The $\mathrm{Ac}_{1}$ and $\mathrm{Ac}_{3}$ temperatures were calculated to be $759{ }^{\circ} \mathrm{C}$ and $883^{\circ} \mathrm{C}$, respectively, according to the following equations ${ }^{[11]}$ :

$$
\begin{aligned}
\mathrm{Ac}_{1}\left({ }^{\circ} \mathrm{C}\right)= & 723-10.7(\% \mathrm{Mn})-16.9(\% \mathrm{Ni})+29.1(\% \mathrm{Si}) \\
& +16.9(\% \mathrm{Cr})+290(\% \mathrm{As})+6.38(\% \mathrm{~W}) \\
\mathrm{Ac}_{3}\left({ }^{\circ} \mathrm{C}\right)= & 910-203(\% \mathrm{C})^{0.5}-15.2(\% \mathrm{Ni})+44.7(\% \mathrm{Si}) \\
& +104(\% \mathrm{~V})+31.5(\% \mathrm{Mo})+13.1(\% \mathrm{~W})
\end{aligned}
$$

Table 1: Chemical composition of tested steel (wt.\%)

$\begin{array}{cccccc}\text { C } & \text { Si } & \text { Mn } & \text { Cr } & \text { B } & \text { V + Ti +RE } \\ 0.24 & 1.5 & 1.5 & 0.52 & 0.004 & 0.053\end{array}$

\subsection{Heat treatment}

The as-cast specimens were subjected to an isothermal normalizing treatment at $900{ }^{\circ} \mathrm{C}$ for $360 \mathrm{~s}$, followed by air cooling. After that, the heat-treated specimens were given an additional isothermal heat treatment and cooled by simultaneously using three cooling methods, namely the upper part was heat-insulating-layer cooling [slow cooling (SC)], the middle part was air cooling [accelerated cooling (AC)] and the bottom was water cooling [fast cooling (FC)], called gradient cooling heat treatment (GCHT). In order to relieve the residual stresses formed during continuous cooling stage, all specimens were tempered at $250{ }^{\circ} \mathrm{C}$ for $360 \mathrm{~s}$.

A schematic of the heat-treating procedures of specimens $\# 1$ and \#2 is presented in Fig. 1a. For the specimen \#1 with a size of $2.5 \mathrm{~mm} \times 20 \mathrm{~mm} \times 120 \mathrm{~mm}$, the GCHT was carried out using the setup shown in Fig. 1b. The isothermal heat treatment was carried out at $900{ }^{\circ} \mathrm{C}$. It is considered that solute $\mathrm{C}$ and $\mathrm{Mn}$ portioning to intercritical austenite could increase the austenite hardenability and stability ${ }^{[12]}$. The higher hardenability could ensure the transition region to have a better strength. Moreover, the lower cooling rate in SC area was also needed to ensure the upper part of specimen to have a higher ductility, which would result in a more stable property gradient. Thus, in the present
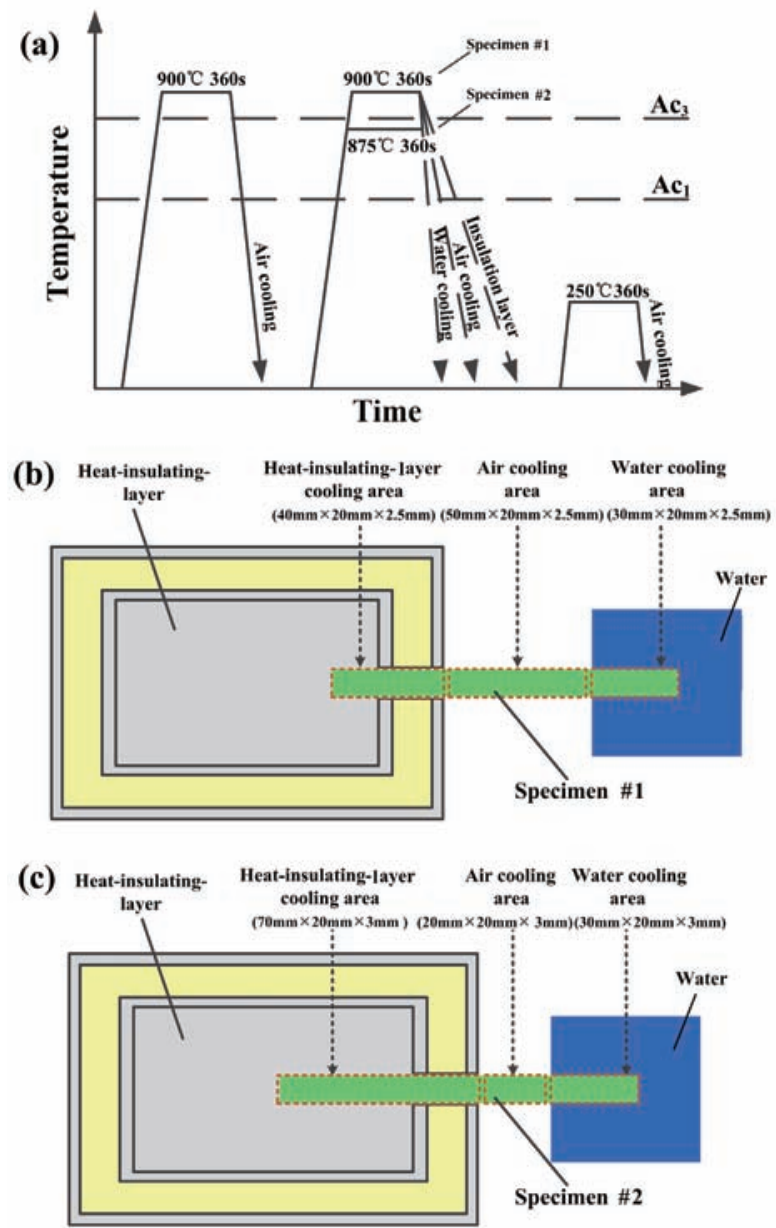

Fig. 1: (a) Heat treatment procedures for obtaining gradient microstructure; (b) and (c) Schematic representation of gradient cooling heat treatment (GCHT) setup for specimens \#1 and \#2 
research, the thermal insulation effect of the heat-insulatinglayer was enhanced by increasing the thickness of the sample and the length of the insulating cloth. Therefore, for specimen \#2 with a size of $3.0 \mathrm{~mm} \times 20 \mathrm{~mm} \times 120 \mathrm{~mm}$, the GCHT was carried out using the setup shown in Fig. 1(c). The isothermal heat treatment was carried out at $875^{\circ} \mathrm{C}$, which was slightly lower than $\mathrm{Ac}_{3}$.

The heat-insulating-layer cooling (SC) was conducted for the upper parts of specimens $\# 1$ and $\# 2$, with a size of $2.5 \mathrm{~mm} \times 20$ $\mathrm{mm} \times 40 \mathrm{~mm}$ and $3 \mathrm{~mm} \times 20 \mathrm{~mm} \times 70 \mathrm{~mm}$, respectively; the air cooling (AC) was conducted for the middle parts of specimens $\# 1$ and $\# 2$, with a size of $2.5 \mathrm{~mm} \times 20 \mathrm{~mm} \times 50 \mathrm{~mm}$ and $3 \mathrm{~mm}$ $\times 20 \mathrm{~mm} \times 20 \mathrm{~mm}$, respectively; the water cooling $(\mathrm{FC})$ was conducted for the bottoms of specimens \#1 and \#2, with a size of $2.5 \mathrm{~mm} \times 20 \mathrm{~mm} \times 30 \mathrm{~mm}$ and $3 \mathrm{~mm} \times 20 \mathrm{~mm} \times 30 \mathrm{~mm}$, respectively, as shown in Fig. 1(b and c).

\subsection{Microstructure and mechanical properties testing}

Optical microscopy (OM) and scanning electron microscopy (SEM) were used to observe the microstructural features of the samples after mechanical polishing and etching in $4 \%$ nital solution. For better phase contrast, color metallography was used according to the method describled in references [13] and [14]. The LePera solution was chosen as color etchant which is a mixture of $1 \%$ sodium metabisulfite $\left(\mathrm{Na}_{2} \mathrm{~S}_{2} \mathrm{O}_{5}\right)$ in distilled water and $4 \%$ picric acid $\left[\mathrm{C}_{6} \mathrm{H}_{2}(\mathrm{NO})_{3} \mathrm{OH}\right]$ in ethyl alcohol with a $1: 1$ volume ratio. Electron backscatter diffraction (EBSD) technique was also used to further analyze microstructure. The EBSD patterns were obtained in a SEM (VEGA 3 XMU, TESCAN, and Czech) equipped with an Oxford Instruments NordlysNano EBSD detector using Aztec. Data were post-processed by CHANNEL 5.0 software to obtain microstructure information.

In order to represent the temperature changing process during heat treatment, the finite element method was used in this work, and the corresponding cooling rate was also approximately calculated.

The mechanical properties of the specimens were measured by hardness test and uniaxial tension test at room temperature. Hardness was measured to obtain the distribution of values at different points along the length orientation on the surface of the sample with the Huayin HRS-150 Rockwell Hardness Tester. Tensile tests were carried out on a material testing system (MTS; 810 testing machine, USA). The tension specimens sectioned from different parts of the samples were used to evaluate mechanical behavior in various positions.

\section{Results}

\subsection{Microstructural evolution}

Figure 2 presents SEM micrographs of sample \#1 with GCHT. It can be seen that an obvious gradient microstructural change is obtained. In the area of SC, it is found that island-like granular bainite (GB) and striped upper bainite (UB), which forms attached to the grain boundaries, distribute uniformly in the matrix (Fig. 2a). These microstructures represent that the bainite transformation occurred in this side of the specimen \#1. However,
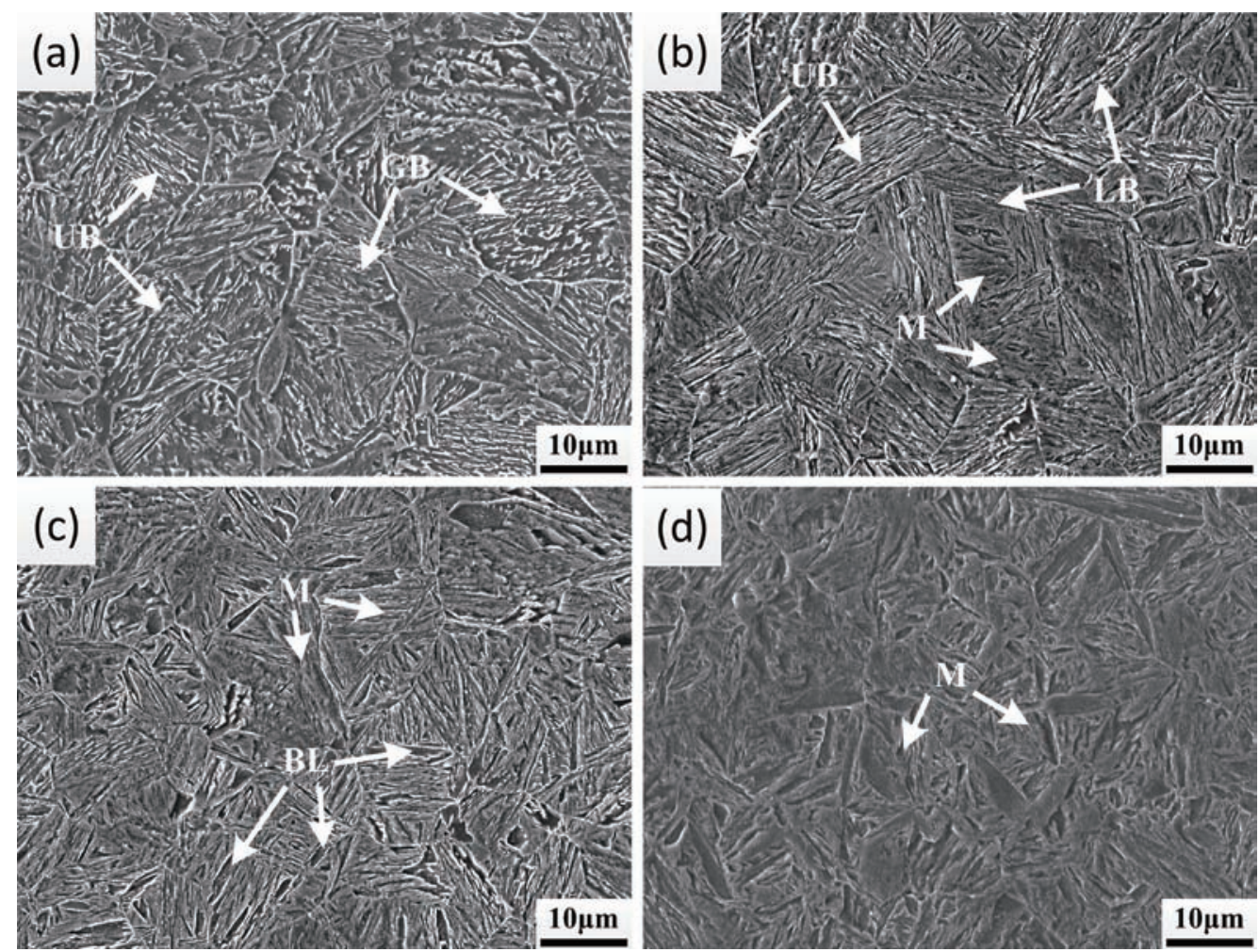

GB-granular bainite, UB-upper bainite, LB-lower bainite, BL-bamboo leaves lath, M-martensite

Fig. 2: Gradient microstructure of specimen \#1: (a) area of slow cooling (SC), (b) upper part and (c) lower part in area of accelerated cooling (AC), (d) area of fast cooling (FC) 
the region of FC exhibits a fully martensitic microstructure (Fig. 2d), which reveals that the bainite transformation did not occur in this region due to the higher cooling rate. Meanwhile, a transition region between the above-mentioned two regions appeared. Due to the heat conduction of steel and the continuity of bainite transformation, multiphase microstructure occurred in this region. When lower bainite (LB) mixed with upper bainite, carbides of lower bainite precipitated within bainitic ferrite plates and nearly paralleled each other (Fig. 2b). However, when lower bainite and martensite together appeared, carbides of LB seemed to move, and black bamboo leaves lath left (Fig. 2c).

As it's difficult to distinguish the difference between lower

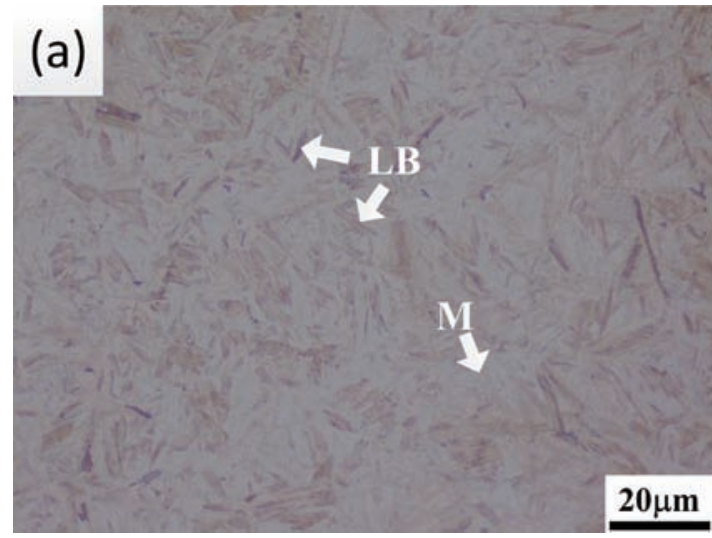

bainite and martensite from morphology like Fig. 2c and $2 \mathrm{~d}$, these two areas of the specimen were etched in a Lepera solution and the Lepera-etched micrographs are shown in Fig. 3. According to the description in references [13] and [14], the bainite was colored brown, whereas martensite and austenite stayed white. The etching was also sensitive to small amount of bainite as can be seen in Fig. 3(a), where a few bainitic laths could be detected in the area of AC, while martensite appeared white. For the area of fast cooling, the martensite transformation was completed and the entire sample became white as shown in Fig. 3b. The fine brown laths emerged in white matrix, which indicates that the black lath is carbide-free bainite, not martensite.

(b)

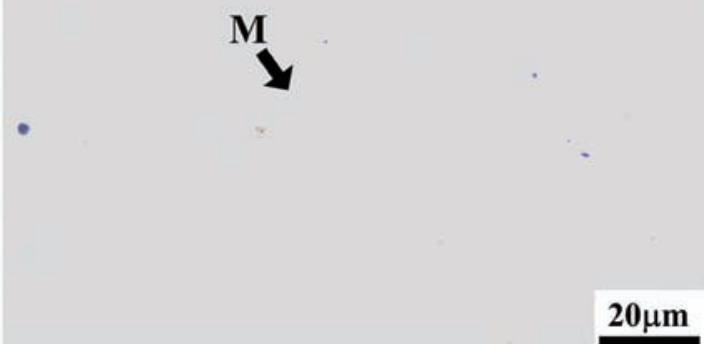

Fig. 3: Color metallography of specimen \#1: (a) area of accelerated cooling (AC) and (b) area of fast cooling (FC)

Figure 4 represents the gradient microstructure of specimen \#2. Obviously, the structural-gradient-material was successfully fabricated by the GCHT manufacturing process. The distinct difference is that the specimen \#2 had a pearlite area at the top of SC area (Fig. 4a), which means eutectoid transformation occurred in this side. Meanwhile, the microstructure with martensite and a little ferrite was also obtained (Fig. 4b) in the FC area. Higher magnification of the transition area (Fig. 5a) showed the granular bainite, upper bainite and a little martensite form in the upper part of AC area. The lower bainite and martensite also appeared in the transition region (Fig. $5 \mathrm{~b}$ and $5 \mathrm{c}$ ). Compared to specimen \#1, the amount of ferrite increased, and as the distance from the FC region decreased, the ferrite decreased gradually and the microstructure was predominantly black phases. However, accurate quantitative analysis of phase composition is difficult by using OM. The morphology of lower bainite is very similar with martensite when it was etched in nital solution and phase separation based on OM from colour-etched samples is often not very precise. The etching colour mainly depends on the local carbon content. Thus, the bainite may also appear white due to its residual carbon content and dislocation density when it was etched in Lepera solution ${ }^{[15]}$. Therefore, an overview EBSD scan was performed for the identification of black phases in the multiphase microstructure.

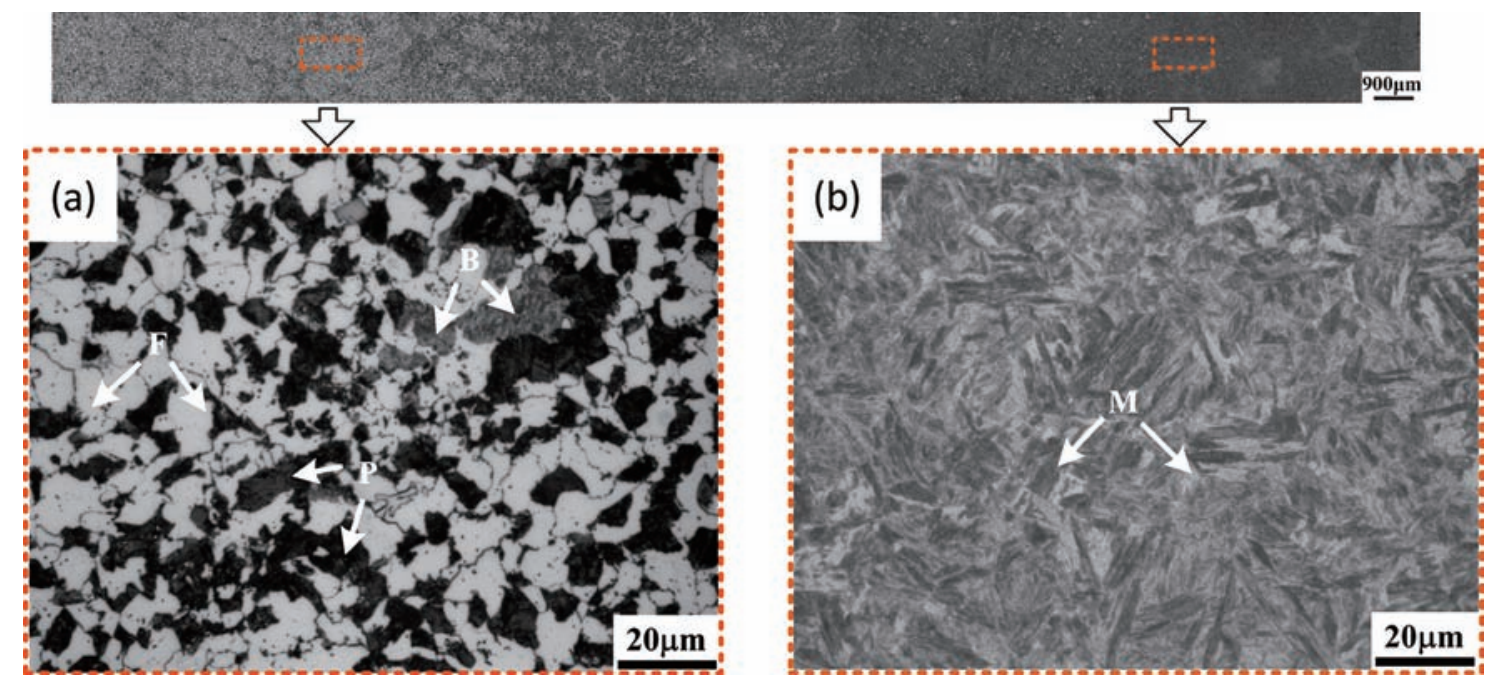

Fig. 4: Gradient microstructure of specimen \#2 produced by GCHT: (a) area of slow cooling (SC) and (b) area of fast cooling (FC) 

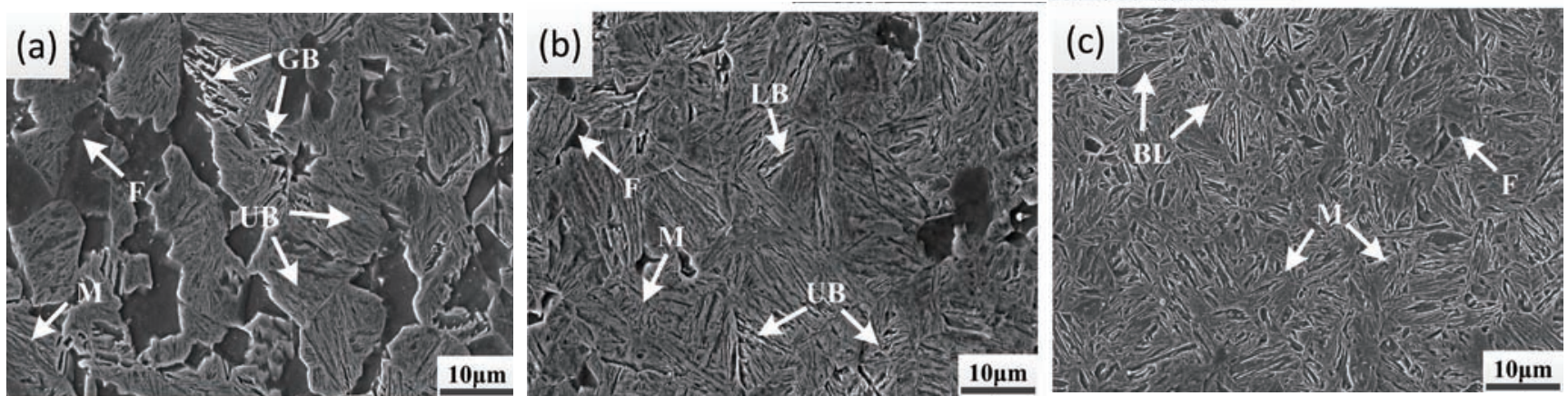

F-ferrite; GB-granular bainite; UB- upper bainite; LB-lower bainite; BL-bamboo leaves lath; M-martensite

Fig. 5: Gradient microstructure of middle area in specimen \#2 produced by GCHT: (a) upper part in middle area, (b) middle part in middle area and (c) lower part in middle area
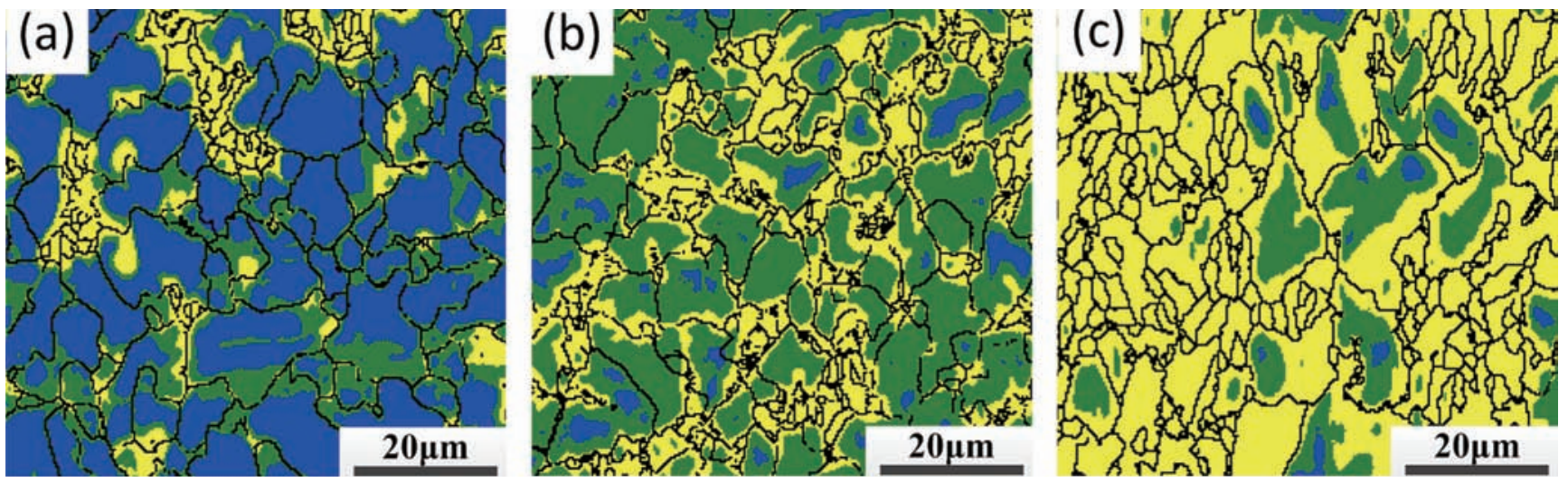

Fig. 6: Phase maps of middle gradient microstructure in heat-treated specimen \#2 with ferrite (blue), martensite (yellow), and bainite (green): (a) upper part in middle area (b) middle part in middle area (c) lower part in middle area

Figure 6 presents the phase maps of the middle part in specimen \#2 by using different thresholds of band slope (BS) values. The BS parameters of the Kikuchi pattern, which is the slope of the intensity change between the background of the pattern and the band ${ }^{[16]}$, were used to distinguish different phases because bainite, ferrite, retained austenite, and martensite have different band slope (BS) values. The BS parameters are on a scale from 0 to 255 . In this case, the ferrite grains were defined as grains with a band slope value of more than 130, bainite with a band slope value between 75 and 130 and martensite grains with a mean band slope value of less than 75 . The multiphase microstructure in Fig. 6 composed of ferrite, bainite, and martensite. The upper part of the middle area consisted of $34 \mathrm{vol} . \%$ of bainite, $48 \mathrm{vol} . \%$ of ferrite, $18 \mathrm{vol} . \%$ of martensite, and the middle part also exhibited the mixed microstructure with $60 \mathrm{vol} . \%$ of bainite, $35 \mathrm{vol} \%$ of martensite and $5 \mathrm{vol} . \%$ of ferrite. In the lower part of the middle area, the bainite and ferrite were reduced to $14 \mathrm{vol} . \%$ and 1 vol. $\%$, respectively, while the martensite increased to $85 \mathrm{vol} . \%$.

\subsection{Mechanical properties}

The Rockwell hardness of the specimen is shown in Fig. 7. It is clear that different positions have different hardness values. For specimen \#1, the average hardness of the upper part was just 40 HRC. However, hardness of the bottom was about $50 \mathrm{HRC}$, which was $25 \%$ higher than the upper part (Fig. 7a). In the middle part, the change of hardness exhibited an approximately linear increase trend with the decrease of distance from FC region, so a transition zone was obtained. Although the hardness tendency of specimen \#2 was similar to \#1 (Fig. 7b), the average hardness of the upper part of specimen \#2 decreased from $40 \mathrm{HRC}$ in specimen \#1 to $22 \mathrm{HRC}$ and the trend of change tends to be more stable. The slope of the increasing curve was also higher than specimen \#1 comparing Fig. 7a with Fig. 7b, and the size of the transition zone decreased with increasing the size of SC area.
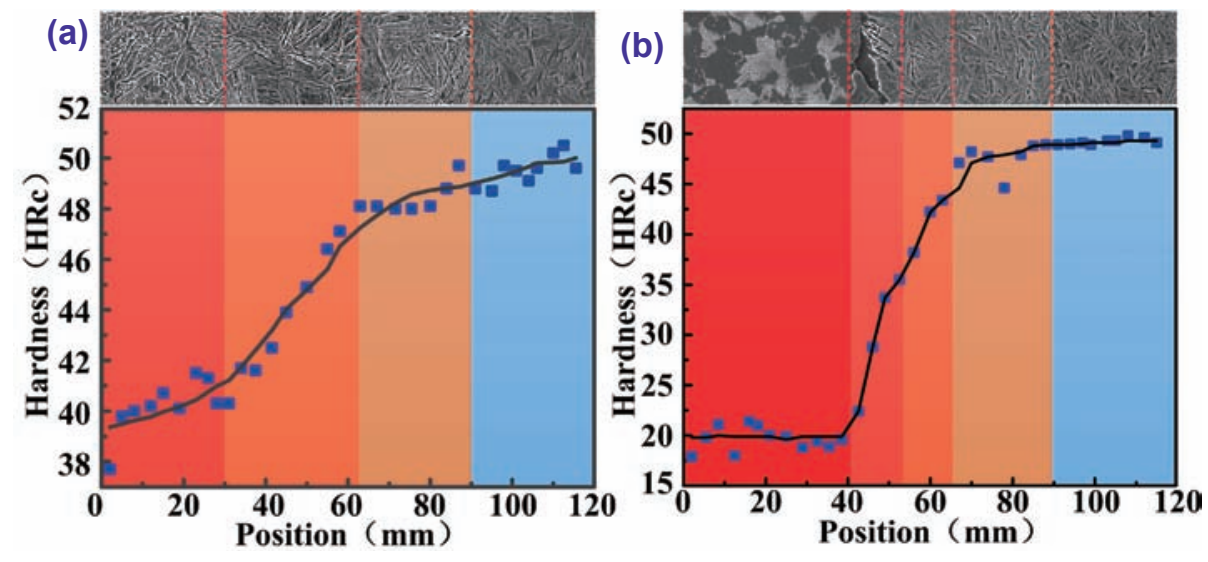

Fig. 7: Hardness of the heat-treated specimen: (a) specimen \#1 and (b) specimen \#2 
Tensile property test was performed on different regions of specimen $\# 1$ and specimen $\# 2$, and the results are shown in Fig. 8. It can be clearly seen that there were different mechanical properties in different regions. For specimen \#1 (Fig. 8a), the ultimate tensile strength of the upper part was 1,340 $\mathrm{MPa}$, and the elongation was $13.8 \%$. In the lower part, the ultimate tensile strength rose up to the maximum while the elongation dropped to the minimum, $1,720 \mathrm{MPa}$ and $6.5 \%$, respectively. Interestingly, the mechanical properties of the middle part had the best combination of tensile strength and ductility $(1,700$ $\mathrm{MPa}$ and $11.1 \%$, respectively). This indicates that the superior comprehensive mechanical properties can be obtained in transition region in present work, which is in contrast to the inferior mechanical properties of the heat affected zone in welding. The same results also occurred in specimen \#2 (Fig. 8b). The strength and ductility of AC area and FC area were almost same as those of specimen \#1. However, the ultimate tensile strength of the SC area was only $830 \mathrm{MPa}$ and elongation percentage was $22.8 \%$.
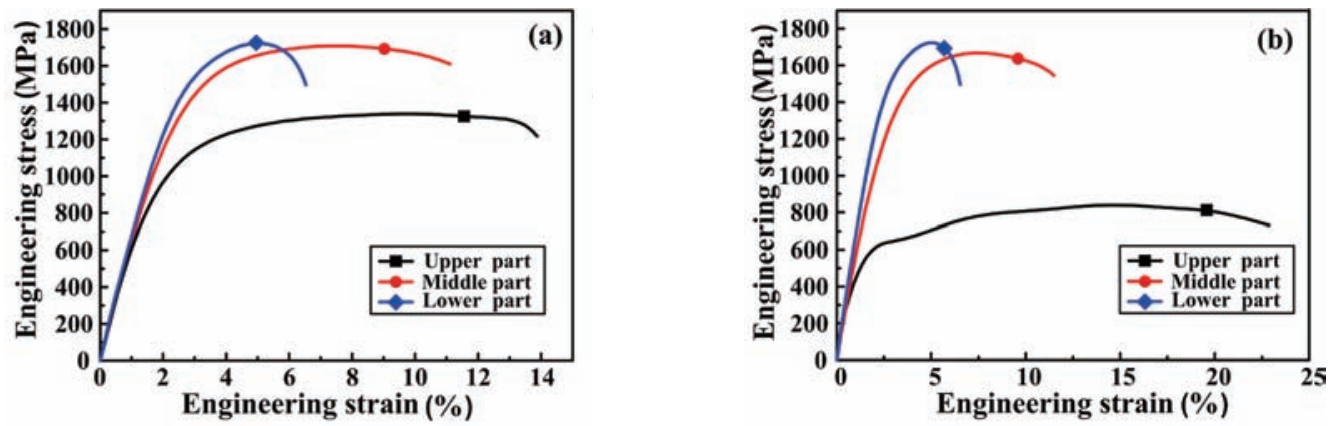

Fig. 8: Tensile curves of different regions in heat-treated specimens: (a) specimen \#1 and (b) specimen \#2

\subsection{Thermal analysis}

Figure 9(a) shows the temperature field of the specimens \#1 and \#2 at the GCHT moment. Points 1-24, marked in Fig. 9(a), were used to study the change in temperature of the steel. Figure $9(\mathrm{~b})$ presents the numerical simulation results of the cooling rate at these points by using the finite element method. It could be found that the different regions in the steel had different cooling rates: normally the slowest in SC area, while the fastest in FC area. Furthermore, the cooling rate at the middle part also increased with the decrease of distance from the FC region. The variation of hardness in steel could be attributed to the microstructural changes caused by different cooling rates. For sample \#1, the microstructure of the upper part was verified as granular bainite and upper bainite (Fig. 2a) with a hardness of $40 \mathrm{HRC}$ that was obtained at a low cooling rate $\left(1.18{ }^{\circ} \mathrm{C} \cdot \mathrm{s}^{-1}\right)$. When the cooling rate was increased to $2.42{ }^{\circ} \mathrm{C} \cdot \mathrm{s}^{-1}$, the microstructure containing lower bainite and martensite appeared (Fig. 2b), and a sharp and continuous increase in hardness (47.6 HRC) was obtained (Fig 7a). As the cooling rate increased from $2.42{ }^{\circ} \mathrm{C} \cdot \mathrm{s}^{-1}$ to $18.78^{\circ} \mathrm{C} \cdot \mathrm{s}^{-1}$, the volume fraction of martensite increased further. A mixture of martensite and lower bainite formed (Fig. 2c), and the hardness was slowly increased to $48.8 \mathrm{HRC}$. Finally, the fully martensitic microstructure (Fig. 2d) and a maximum hardness of $50 \mathrm{HRC}$ were acquired at the fastest cooling rate $\left(41^{\circ} \mathrm{C} \cdot \mathrm{s}^{-1}\right)$. For sample \#2, the decrease of minimum cooling rate to $0.76{ }^{\circ} \mathrm{C} \cdot \mathrm{s}^{-1}$ caused the formation of polygonal ferrite and pearlite (Fig. 4), and hardness was just 20 HRC. However, the multiphase microstructure with ferrite, granular bainite, upper bainite and a little martensite formed already at a cooling rate of $0.93{ }^{\circ} \mathrm{C} \cdot \mathrm{s}^{-1}$ (Fig. 5a). When the cooling rate increased from $0.98^{\circ} \mathrm{C} \cdot \mathrm{s}^{-1}$ to $1.73{ }^{\circ} \mathrm{C} \cdot \mathrm{s}^{-1}$, the granular bainite almost vanished and the amount of lower bainite and martensite had a significant increase (Fig. 5b). As the cooling rate increased further, the mixture of lower bainite and martensite and martensitic microstructure also occurred (Fig. 5c and Fig. 4b).

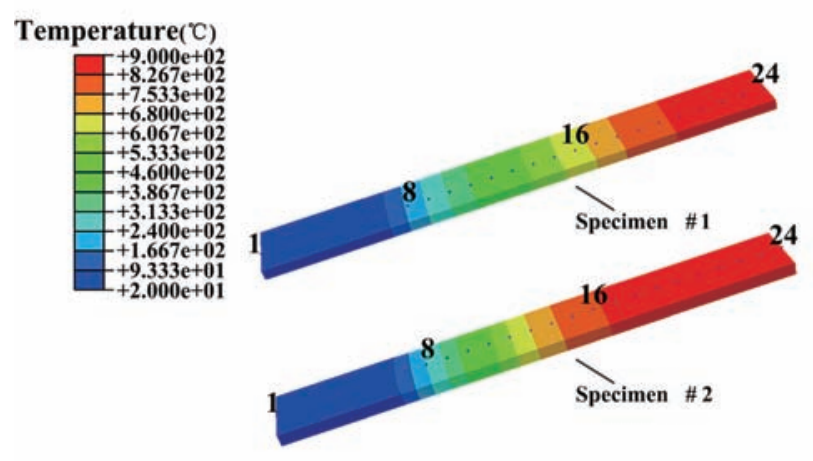

(a)

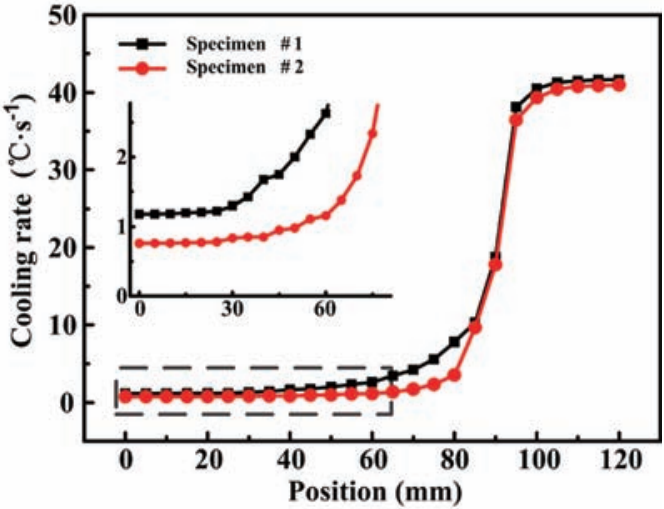

(b)

Fig. 9: (a) Temperature fields of specimens \#1 and \#2 at GCHT moment and (b) cooling rate distribution patterns of specimens by using qualitative numerical simulation 
Figure 10 shows the change in temperature of point 8 from the moment that the steel was taken out from the furnace to the moment of cooling at $900 \mathrm{~s}$ in specimen \#2. It could be observed that the cooling rate at the same point was not constant during the continuous cooling process. The velocity was slow when it was cooled in intercritical region, but was getting faster as time went by. This phenomenon could be attributed to the unique position in the specimen. Even though the upper part of the transition region (point 8 ) was protected in the insulating cloth, it was still influenced by the FC area due to the heat conduction of steel as the specimen was cooled further.

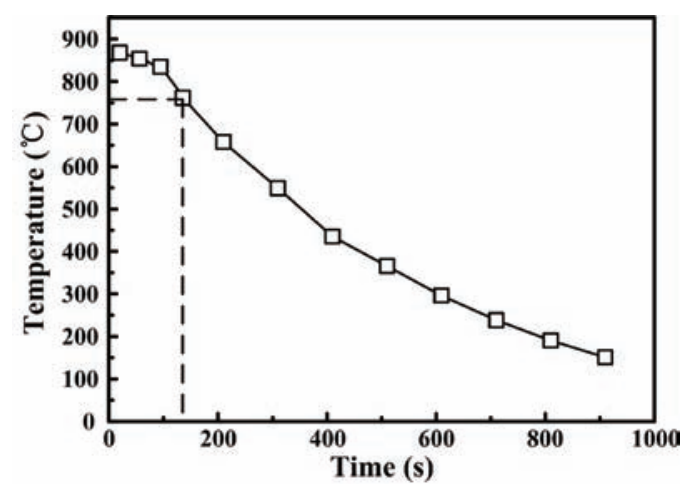

Fig. 10: Temperature change of point 8 (from the moment that the steel is taken out from the furnace to the moment of cooling at $900 \mathrm{~s}$ in the specimen \#2.)

\section{Discussion}

The microstructure evolution of the specimen varies with the change of cooling rate, as shown in Fig. 2a and d. In the SC area of specimen $\# 1$, the lowest cooling rate ensures that carbon atoms have sufficient time to concentrate in $\gamma / \alpha$ interface. Since high carbon content can improve the stability of austenite, some austenite is retained at room temperature while the rest of it transforms into martensite and bainite. Thus, the M/A islands can be formed ${ }^{[17]}$. It's well-known that $\mathrm{M} / \mathrm{A}$ islands can dramatically enhance the performance as a hard second phase. In the FC area, the cooling rate reaches the maximum value and the diffusionless transformation occurs in the experimental steel ${ }^{[18,19]}$. Austenite transforms to martensite (Fig. 2d). The high dislocation density and the presence of internal twins in martensite may result in its high strength, hardness and poor plasticity ${ }^{[20,21]}$. For the intermediate zone, the FC area has a noticeable effect on the middle part so that its cooling rate is much higher than the normal air cooling. Therefore, the cooling rate increases as the distance from the water-cooled zone decreases and lower bainite gradually forms. When the cooling rate increases to a certain critical value, martensite transformation begins to act. Compared to granular bainite, the lower bainite has a higher hardness, which is induced by the higher dislocation density, the higher internal stress and the finer bainitic ferrite laths ${ }^{[22,23]}$. Hence, the hardness is improved with lower bainite and martensite increasing (Fig. 7a).

As the cooling rate further increases, the acicular carbide-free bainite forms gradually since carbon atom has not enough time to diffuse and silicon element can retard the formation of cementite precipitation in austenite ${ }^{[24]}$. When the acicular-like lower bainite appears in martensite matrix, it can divide the prior austenite grain and refine the final martensite substructures, which will greatly enhance the fracture toughness. On the other hand, the improved ductility can also be attributed to the fact that the microcracks initiating at one lower bainite area can be stopped at another lower bainite area when it deforms in association with martensite ${ }^{[25,26]}$. As a result, the steel with a lower bainite/ martensite mixed microstructure possesses a better combination of strength and elongation than that with a full martensite microstructure.

For specimen \#2, the heat insulation effect is significantly enhanced due to the increase in length of insulating cloth and thickness of the sample. The cooling rate of SC area is so slow that the carbon atoms have enough time to conduct long-range diffusion. Ferrite and cementite are formed due to the eutectoid decomposition in austenite ${ }^{[27]}$. As a ductile phase, the ferrite in a high content can substantially enhance plasticity and reduce strength (Fig. 8a). For the upper part of the transition region, the cooling rate is lower when it is cooled in the intercritical region (Fig. 10) due to the better insulation effect and the austenite is partially transformed to ferrite. But as the sample is cooled further, the cooling rate is gradually increased because of the decrease of heat transfer with decreasing FC area temperature. The granular bainite, upper bainite and a little martensite are acquired (Fig. 5a and Fig. 6a). With the cooling rate increasing further, eutectoid transformation is replaced by bainite transformation and martensite transformation. The amount of ferrite decreases gradually and pearlite almost disappears. The bainite and martensite become the dominant components of the microstructure (Fig. 6). However, due to the lower temperature during heat treatment, which is slightly lower than $\mathrm{Ac}_{3}$, the matrix is partially transformed to austenite in the process of heating. Solute $\mathrm{C}$ and $\mathrm{Mn}$ portioning to the intercritical austenite increases the austenite stability and hardenability, compared to the austenite in the homogeneous alloy ${ }^{[12]}$. Hence, there is still a small amount of $\delta$-ferrite in the room temperature structure (Figs. 5 and 6), and the austenite is more sensitive to the cooling rate. Martensite transformation can occur at a lower cooling rate, which causes a sharp increase of hardness in the transition region. The Mn enrichment in the austenite can depress bainite transformation temperature and driving force ${ }^{[28]}$, and accelerate the formation of lower bainite. Therefore, the major structure in the transition region is still the multiphase microstructure with martensite and lower bainite. The intermediate area with excellent mechanical properties is also obtained.

In summary, the different microstructures with different mechanical properties can be obtained via changing cooling velocity. The SGMs can be designed to meet different requirements in practical applications. However, the hardenability of steel and deformation during heat treatment may also have an important influence on the performance of the material when the technology is applied in industrial applications. Hence, further investigation is needed to reveal the effect of these factors on steel under different heat treatment conditions. 


\section{Conclusions}

(1) The structural-gradient-materials (SGMs) were successfully prepared by using the gradient cooling heat treatment processes in a $\mathrm{Mn}-\mathrm{Si}-\mathrm{Cr}-\mathrm{B}$ bainitic cast steel.

(2) The SGM with a heterogeneous microstructure showed a good ductility $(\sim 13.8 \%)$ at one end due to the granular bainite, and an excellent ultimate strength $(\sim 1,720 \mathrm{MPa})$ at the other end due to the lath martensite. Moreover, it is noticeable that a transition region with a superior combination of tensile strength and ductility (1,700 MPa and $11.1 \%)$ was successfully produced, which could be attributed to the formation of acicular carbidefree bainite and the refinement of martensite substructures.

(3) The different gradient microstructure with different properties could be designed via controlling the gradient of cooling rate. The optimized SGM with a gradient microstructure from ferrite and pearlite to martensite also had a good property transition region and a better ductility $(22.8 \%)$ at one end. It may have a greater potential for application in fabrication of dual-property automobile parts.

\section{References}

[1] Eddahbi M, Borrego A, Monge M A, et al. Microstructure gradient after hot torsion deformation of powder metallurgical 6061 Al alloy. Materials Science and Engineering A, 2012, 555(10): 154-164.

[2] Kawase M, Tago T, Kurosawa M, et al. Chemical vapor infiltration and deposition to produce a silicon carbide-carbon functionally gradient material. Chemical Engineering Science, 1999, 54(15): 3327-3334

[3] Jafarian M, Rizi M S, Jafarian M, et al. Effect of thermal tempering on microstructure and mechanical properties of Mg-AZ31/Al-6061 diffusion bonding. Materials Science and Engineering A, 2016, 666: 372-379.

[4] Qu H P, Li P, Zhang S Q, et al. The effects of heat treatment on the microstructure and mechanical property of laser melting deposition Y-TiAl intermetallic alloys. Materials \& Design, 2010, 31(4): 22012210.

[5] Baggerly R G. Failure of steel castings welded to heavy truck axles. Engineering Failure Analysis, 2004, 11(1): 115-125.

[6] Bhadeshia H K D H, Christian J W. Bainite in steels. Metallurgical Transactions A, 1990, 21(3): 767-797.

[7] Chen X, Vuorinen E, Grahn J. In-situ SEM observation on fracture behavior of austempered silicon alloyed steel. China Foundry, 2009, 6(3): 185-190.

[8] Rodrigues P C M, Pereloma E V, Santos D B. Mechanical properities of an HSLA bainitic steel subjected to controlled rolling with accelerated cooling. Materials Science and Engineering A, 2000, 283(1): 136-143.

[9] Li Z, Wu D, Lü. H S, Fang S R. Continuous Cooling Transformation Behaviour of C-Si-Mn TRIP Steel. Journal of Iron and Steel Research, International, 2007, 14(5): 277-281.

[10] Sung H K, Shin S Y, Hwang B, et al. Effects of carbon equivalent and cooling rate on tensile and Charpy impact properties of high- strength bainitic steels. Materials Science and Engineering $A$ 2011, 530(1): 530-538.

[11] Leslie W C. The Physical Metallurgy of Steels. Hemisphere Publishing Corporation, Washington, 1981, 257.

[12] Lee S, De Cooman B C. Effect of the Intercritical Annealing Temperature on the Mechanical Properties of 10 Pct Mn Multiphase Steel. Metallurgical and Materials Transactions A, 2014 45(11): 5009-5016.

[13] Girault E, Jacques P, Harlet P, et al. Metallographic Methods for Revealing the Multiphase Microstructure of TRIP-Assisted Steels. Materials Characterization, 1998, 40(2): 111-118.

[14] Lepera F S. Improved etching technique for the determination of percent martensite in high-strength dual-phase steels. Metallography, 1979, 12(3): 263-268.

[15] Zaefferer S, Romano P, Friedel F. EBSD as a tool to identify and quantify bainite and ferrite in low-alloyed Al-TRIP steels. Journal of Microscopy, 2008, 230(3): 499-508.

[16] Ryde L. Application of EBSD to analysis of microstructures in commercial steels. Materials Science and Technology, 2006 22(11): 1297-1306.

[17] Duan L N, Chen Y, Liu Q Y, et al. Microstructures and Mechanical Properties of X100 Pipeline Steel Strip. Journal of Iron and Steel Research, International, 2014, 21(2): 227-232.

[18] Malheiros L R C, Rodriguez E A P, Arlazarov A. Mechanical behavior of tempered martensite: Characterization and modeling Materials Science and Engineering A, 2017, 706: 38-47.

[19] Prawoto Y, Jasmawati N, Sumeru K. Effect of Prior Austenite Grain Size on the Morphology and Mechanical Properties of Martensite in Medium Carbon Steel. Journal of Materials Science \& Technology, 2012, 28(5): 461-466.

[20] Tu M Y, Hsu C A, Wang W H, et al. Comparison of microstructure and mechanical behavior of lower bainite and tempered martensite in JIS SK5 steel. Materials Chemistry and Physics, 2008, 107(2): 418-425.

[21] Niino T, Inoue J, Ojima M, et al. Effects of Solute Carbon on the Work Hardening Behavior of Lath Martensite in Low-Carbon Steel. ISIJ International, 2017, 57(1): 181-188.

[22] Sajjadi S A, Zebarjad S M. Isothermal transformation of austenite to bainite in high carbon steels. Journal of Materials Processing Technology, 2007, 189(1): 107-113.

[23] Abbaszadeh K, Saghafian H, Kheirandish S. Effect of bainite morphology on mechanical properties of the mixed bainitemartensite microstructure in D6AC steel. Journal of Materials Science \& Technology, 2012, 28(4): 336-342.

[24] Kozeschnik E, Bhadeshia H K D H. Influence of silicon on cementite precipitation in steels. Materials Science and Technology, 2008, 24(3): 343-347.

[25] Tomita Y, Okabayashi K. Mechanical properties of $0.40 \mathrm{pct} \mathrm{C-Ni-}$ Cr-Mo high strength steel having a mixed structure of martensite and bainite. Metallurgical Transactions A, 1985, 16(1): 73-82.

[26] Tomita Y, Okabayashi K. Improvement in lower temperature mechanical properties of 0.40 pct C-Ni-Cr-Mo ultrahigh strength steel with the second phase lower bainite. Metallurgical Transactions A, 1983, 14(2): 485-492.

[27] Ridley N. A Review of the Data on the Interlamellar Spacing of Pearlite. Metallurgical Transactions A, 1984, 15(6): 1019-1036.

[28] Fang H S, Feng C, Zheng Y K, et al. Creation of Air-Cooled Mn Series Bainitic Steels. Journal of Iron and Steel Research, International, 2008, 15(6): 1-9.

This work is financially supported by the National key research and development program (No. 2017YFA0403700) and the Natural Science Foundation of China (No. 51701080). 